\title{
Developing graduate attributes in an open online course
}

\author{
Michael Rowe
}

\begin{abstract}
In an increasingly connected world where solving complex problems is not possible by solitary experts, educators and learners need opportunities to develop ways of thinking that allow them to engage with the dynamic and complex situations that arise in the world. The development of graduate attributes has been suggested as one way in which students can be prepared as active agents of social good. However, there are significant challenges with respect to developing these graduate attributes. This paper argues that the use of authentic learning in the design of open online courses may provide a structure for educators to develop generic graduate attributes.

The use of collaborative technologies that are informed by authentic learning enables new forms of communication that allow students to fully engage with the academic process in ways that are difficult to achieve with traditional, classroom-based teaching methods. This study made use of a blogging platform to create a collaborative open online course using principles of authentic task design in order to develop graduate attributes in undergraduate physiotherapy students.

The study used an interpretive, qualitative design that gathered data via focus group discussions. Transcripts were analysed inductively in order to determine categories, which were then analysed in relation to the graduate attributes of the institution in which the study took place. Student discussions suggested that they had developed at least some components of generic graduate attributes, including an approach to learning that was personal and internally motivated, the ability to consider alternative points of view and acknowledge different perspectives, the confidence to challenge knowledge and authority, and skills as empathic communicators.
\end{abstract}

\section{Background}

Higher education institutions from around the world are emphasising that their graduates must do more than simply reproduce the discipline-specific knowledge and skills that form the core of most university courses (Barrie, 2007). Higher education must encourage students to do more than simply accumulate facts and should aim to fulfill a need in society for spaces that encourage a deep and critical investigation into 
the nature of our world (Ovens, Wells, Wallis \& Hawkins, 2011). In an increasingly connected society where solving complex problems is not possible by solitary experts, educators and learners need opportunities to develop the skills, knowledge and mindsets that are necessary for them to participate in dynamic and complex situations (Cormier \& Siemens, 2010). The development of these non-discipline specific skills informs the rationale for the integration of graduate attributes into the higher education context.

\section{Practitioner Notes}

What is already known about this topic

- Open online courses are increasingly being explored as alternatives to traditional methods of higher education provision.

- The development of generic graduate attributes is both important in higher education, and difficult to achieve.

- Teaching frameworks like authentic learning offer theoretically-informed models for educators to design courses that prepare students beyond their discipline-specific boundaries.

What this paper adds

- The paper describes the process of integrating authentic learning and open online courses in order to develop graduate attributes within a professional programme.

- The integration of authentic learning principles with emerging technology can facilitate the development of generic graduate attributes.

Implications for practice and/or policy

- Educators who are interested in creating open online courses that aim to develop graduate attributes should consider using authentic learning principles in their learning environment design.

- The development of higher level outcomes like graduate attributes must be facilitated with task-based activities, meaning that open online courses must do more than simply make content available.

One way of thinking about the development of graduate attributes is as a process of engagement by the student within the activities of a course (Barrie, 2007). In this conception of development there is a shift in emphasis from the teacher to the student. At the level of engagement it is not the course content or even the graduate attributes 
that are the focus of the teaching process but rather the way that students engage in learning. In this characterisation the development of graduate attributes is not separate to the students' learning but is a product of how they engage with the curriculum (ibid.). Graduate attributes are therefore not additive curriculum outcomes that are supplemental to more important disciplinary content, but rather are integrated into higher level learning outcomes that are transformative in nature. In other words, the development of graduate attributes is not possible by adding additional courses on the subject, but instead requires the integration of student learning activities into existing modules that cause them to think and behave according to the attributes that one wants to develop.

The integration of graduate attributes into professional courses challenges us to rethink what we mean by a course and to ask where the value lies (Cormier \& Siemens, 2010). As free, high- quality content becomes increasingly available online there is a shift away from thinking of a course in terms of the information that it contains. Rather, the benefit of higher education is in the opportunities for interaction, debate and the negotiation of knowledge (ibid.). In other words, a university course has value if we consider it as a space for student engagement rather than as a container of information. With the emergence of social networks and collaborative technologies like blogging this "negotiation of knowledge" can be scaled beyond the walls of the classroom and the restrictions of physical space. The use of these tools and services enables new forms of communication and collaboration, allowing students and educators to fully engage with the academic process and allowing for new forms of teaching and learning practices in and out of the classroom (ibid.).

Open online courses (OOC) are the subject of increasing attention in higher education, as they are informed by the ideals of openness in education, the free sharing of knowledge, and a desire to open access to learning that is not limited by demographic, economic, and geographical constraints (Yuan \& Powell, 2013). Open online courses introduce broader learning connections, opportunities for enhanced collaboration and exposure to different perspectives, all of which change the learning context in ways that may improve student learning (Cormier \& Siemens, 2010; Fini, 2009). The benefits of OOC include the development of skills that exist "outside" the formal curriculum, including lifelong learning, personal knowledge management and the effective use of web-based platforms and services as part of the learning process (ibid.). Through the broader social connections, opportunities for collaboration, and exposure to many different perspectives, the learning environment is significantly altered and made increasingly complex, which enhances the potential for meaningful learning (Parker, Maor \& Herrington, 2013). Open online courses therefore have the affordances necessary to develop the kinds of graduate attributes that have value in an increasingly complex and globally connected world (Bozalek \& Watters, 2014). 
It was in this context that an OOC in Professional Ethics was designed by the author in collaboration with two colleagues from Physiopedia, a non-profit organisation based in the United Kingdom. The aim of this study was to determine if generic graduate attributes could be developed using principles of authentic learning in an open online course.

\section{Method}

The study used an interpretive, qualitative design that gathered data via focus group discussions and group interviews. These data gathering methods were appropriate to encourage course participants to make meaning through the emergence of concepts during the process that individuals may not have developed in isolation (Cohen, Manion \& Morisson, 2007).

This study took place in October, 2013 at a South African university physiotherapy department. The population included 52 third year undergraduate physiotherapy students, as well as 28 qualified physiotherapists from around the world (Canada, Estonia, India, New Zealand, Saudi Arabia, South Africa, United Kingdom, and United States). These qualified physiotherapists were recruited via various social media channels, as well as the Physiopedia mailing list and fulfilled an important role in terms of implementing the authentic learning principles. They were not interviewed for this study. Nineteen students made themselves available for the focus group discussions and eight were purposively selected to provide a diverse sample.

\section{Course design}

The main aim of the Professional Ethics course at this institution is to help students learn how to engage with, and negotiate, the complex ethical dilemmas that they may encounter in clinical practice. The course was previously taught with a combination of lectures, small group work, classroom discussion and debate. The final assessment consisted of a learning portfolio that stu- dents had developed over the course of the year, providing a range of evidence of their learning. Changes to the module for this study were informed by Barrie's (2007) categorisation of the con- ceptions of graduate attribute development, as well as principles of authentic learning. According to Barrie (2007), graduate attributes should be understood through Engagement in that they are "learnt through the way students engage with the course's learning experiences" (Barrie, 2007, 445). In other words, how students engaged with the tasks in the module was of primary importance.

These tasks were informed by principles of authentic learning, which provided a structured way to design the learning environment. Authentic learning is informed by 
situated cognition, which suggests that, when knowledge and context are separated, knowledge is seen as a product of learning, rather than as a set of tools that can be used to solve problems (Herrington \& Oliver, 2000). Student activity within an authentic context was therefore emphasised during this course, rather than the content or teaching methods used. It was important to avoid a rigid framework of educatorsanctioned content and to rather design an environment that enabled a "multifaceted web of intersecting concepts, ideas, and connections" (Cormier \& Siemens, 2010, 36). For this reason the decision was made not to use the university's Learning Management System, which did not provide the necessary features to implement this environment. Instead, students created their own personal learning environments (PLE) using WordPress.com, a free and open source blogging platform. Personal learning environments address the inherent problems with institutional learning management systems (LMS) by allowing students the freedom to experiment with their own paths to understanding, rather than the more rigid and prescriptive format of the traditional LMS (Wilson et al., 2007). In their blogs, students were able to create a dynamic curriculum via their own conversation, discussion and interaction, very much in line with the concept of a PLE that enabled them to create the course content they needed in order to achieve the learning outcomes.

The Ethics course was a credit-bearing component of the third year curriculum at the University of the Western Cape, and ran over a 6 week period from August-September, 2013. The module outline was posted on Physiopedia, using a Creative Commons license that made the course con- tent and structure freely available to anyone, with the additional permissions to re-use, re- distribute and modify the existing course, with attribution. The module included a variety of topics and learning outcomes but no specified content. In other words, broad topics were introduced for discussion but students were required to find their own content to bring into the course. These topics included Equality, Ethics and morality, Meaningful life and death, and Empathy in professional practice. The topics were arranged in a weekly schedule that provided structure for those students who needed assistance with time management. However, they were able to work through the topics at their own pace and in whatever order they preferred. In other words, students decided when and how they would participate in the course.

In order to address a topic, which was presented as a reading, video, image or combination, students needed to first review it and write-but not publish-a reflective blog post representing their understanding of the topic. In order to develop their thinking around the topics, they were then encouraged to develop their own line of inquiry (Ovens et al., 2011). This included developing research questions, conducting searches to find additional resources, and integrating those resources into a final synthesis of the topic, which was then published as a public blog post. In addition, students were encouraged to incorporate the blog posts of other students into their 
writing, as well as comment on each others work. The international therapists introduced their own local context and understanding into the online discussion by writing their own reflections and commenting on students' blog posts. This lead to a significant number of shared experiences and diversity of opinion and perspective on various ethical dilemmas in the health context, in line with the principles of authentic learning. Table 1 below presents the elements of authentic learning, along with descriptors explaining how the element was implemented in the course.

\section{Data collection and analysis}

Focus group discussions were conducted 1 week after the Professional Ethics course concluded and all students who completed the course were invited to participate, with eight eventually being selected. As a result of the logistical challenges involved with having two focus group discussions with four students in each group, the researcher conducted one focus group, consisting 
Table 1: Nine elements of authentic learning and their implementation in the module

Authentic learning principle

Provide authentic contexts that reflect

the way the knowledge will be

used in real life

Provide authentic tasks and activities

Provide access to expert performances and the modeling of processes

Provide multiple roles and perspectives

Support collaborative construction of knowledge

Promote reflection to enable abstractions to be formed

Promote articulation to enable tacit knowledge to be made explicit

Provide coaching and scaffolding by the teacher at critical times

Provide for authentic assessment of learning within the tasks
How the element was applied in the course

Students were asked to reflect on their own clinical experiences and ethical dilemmas, and to bring these experiences into their blog posts

Students were provided with readings and additional resources that were based in reality, ie, news reports, interviews with patients, etc. which meant that their reflections needed to integrate the course concepts with reality

Qualified physiotherapists from around the world were also blogging and sharing not only their experiences but their responses. This gave students insight into how a practicing physiotherapist would deal with the situation

Resources provided were carefully selected to present multiple points of view to the students, so that a single perspective did not dominate. In addition, students were encouraged to find their own resources in order to support different perspectives

Students, facilitators and qualified professionals were all reading and blogging together

Each blog post was a reflection by a student, facilitator or physiotherapist. Students were encouraged to review and modify their posts based on their continued engagement, so the reflective process was extended over time

The act of publishing a public blog post is a form of commitment to a belief. Students were required to present their arguments in a public form (the blog) in a way that made them accountable to their thinking

The facilitators and qualified physiotherapists were not only writing their own reflective blog posts, but commenting on students work. The feedback was aimed at directing students' thinking towards higher levels of understanding

The students' blog posts were used for the assessment task in the module. In other words, there was no additional test or assignment, only the blog. This meant that the work that students put into the blog was not "lost" in the final assessment

of four students, and two group interviews consisting of two students each. All discussions lasted about one hour and were recorded. The audio recordings were sent away for transcription, during which they were anonymised. The anonymised transcripts were sent to student participants for member checking. 
The transcripts were analysed inductively in order to determine the themes that emerged from the student discussion (Cohen et al., 2007). This was done by using open coding to first identify phrases with similar meanings in the students' discussions, and then organising them into categories based on similarity of content (Elo \& Kynga€s, 2007). The emergent categories were then analysed in relation to the University of the Western Cape Charter of Graduate Attributes in order to determine if the student discussion provided any evidence of the development of graduate attributes. The graduate attributes of this institution were used as an indicator of attribute development because there is no single set of canonical graduate attributes against which to evaluate change.

\section{Ethics considerations}

The project received ethics clearance from the university's Research Committee (project registration: 13/05/18) and permission to conduct the study was obtained from the Registrar of the University and the Head of the Physiotherapy Department. Students were invited to participate in the focus group discussions 1 week after the course was completed and also offered the option of withdrawing from the study at any stage. The data collected were anonymous and students were asked to sign a confidentiality binding form, agreeing not to discuss other participants outside of the study.

Results and discussion

This study found that a subset of generic graduate attributes could be developed using a combination of authentic learning principles in the context of an open online course. While specific causal relationships were not investigated, it was possible to make inferences regarding the influence of the course activities on the develop of different ways of thinking about professional development and learning. The following themes were identified during the analysis: Internal motivation; Dealing with difference; Challenging knowledge and authority; and Empathic communication. These themes are presented below, along with supporting quotes, and then discussed in relation to the development of graduate attributes.

\section{Internal motivation}

In response to a question related to the role of the course in changing how these students' thought about learning, they reported that the approach to the learning tasks in the course encouraged them to take responsibility for their own learning, rather than to take a passive role in the process. The following quotes are presented in support of the claim.

S1: "I think if you learn to think for yourself you'll find it easier to challenge different opinions-so this course helped me to think for myself.. . because it's more 
about knowing yourself and knowing why you think the way you do-so you'll be more confident in expressing yourself to someone else."

S2: "I think it just made me feel responsible for my own learning. I could choose how much input I wanted to put in and that would determine how much I actually got out from the course. At the same time people that don't put in the effort don't realise what they're missing out on-but I guess that's their own fault. I think you can get a lot out of things when you can choose how much effort you want to put into it."

S3: "You had to put it into your own life context. You never really could understand what the next topic was unless you thought back onto a time where you experienced it.. . and then it started to make sense to me-just having the word up there [on the screen] wasn't helping too much; so you still have to provide your own context and your own information."

Lifelong learning, as described in the UWC Charter of Graduate Attributes, states that graduates should be confident lifelong learners, committed to and capable of continuous collaborative and individual learning and critical reflection for the purpose of furthering their understanding of the world and their place in it. The students in this project reported that the way the course was structured encouraged them to take responsibility for their learning. They noted that the course structure required them to actively engage in the learning process by putting it in their "own life context." It is important to note that there is some evidence to suggest that students who do not have the relevant participatory literacies and who lack self-determination may not benefit as much from task- based online courses-such as this one-compared to content-based courses (Beaven et al., 2014). Course designers developing these kinds of open online courses must therefore be aware of the assumptions they make about their student participants and ensure that adequate support is provided for students.

\section{Dealing with difference}

When students were asked if the course changed the way they thought about other people's opinions and points of view, they reported that the variety of perspectives allowed them to reflect on their own thinking. However, it did not necessarily lead to a change of opinion; just an acknowledgement that other world views exist.

S1: “.. . when you see a topic you immediately form this opinion, and when I read [the] other blogs you just calm down and you kind of expand your thinking, just openminded, and then you write from both sides. So a lot of the time.. . you say this is your

opinion-that didn't really change; but.. . having read other people's different opinions you can see that there is another side, so [you're] not so one-sided." 
S2: "I think a lot of the concepts we had never thought of before; and that was challenging when you're not sure what to say about something. [Sometimes] I felt like I wanted to say more than what I actually wrote in fear of someone going, oh, well, that's wrong... .. So that was initially quite scary.”

S3: “.. . some people do have good experiences, so when you read that you're like, okay, there is another side; it's not only you in the world. There's also other people and they've experienced different things."

Interpersonal flexibility and the confidence to engage across difference is a graduate attribute that describes an ability to interact with people from different backgrounds and for students to have the emotional insight and imagination to understand the viewpoints of others. During this course students were confronted with topics and reflections from peers and professional colleagues that challenged their ways of thinking and allowed them to consider alternative points of view. As part of holistic and meaningful learning practices, students must not only develop their confidence but also be aware of their ignorance and doubt, in order to better inform and guide their own learning. Through reflecting on their understanding of the world, they were forced to ask questions that deepened their understanding (Ovens et al., 2011). This is not always easy and students found themselves in uncomfortable positions that challenged their understanding and ways of thinking.

\section{Challenging knowledge and authority}

When students were asked if participation in the course changed how they thought about challenging ideas and people, they reported that it was liberating to know that they were free to challenge and to think for themselves; that they did not have to believe something simply because someone in authority had said it.

S1: "It just emphasised the importance of having evidence to support your opinion in some way, so if you would like to challenge someone's view you need to present some form of evidence, and I think that's what I learned, one of the things from the course, that you can't just say, oh, I disagree and this is what I would do, but to provide them with good evidence and backing to your thoughts."

S2: "It was the way in which people commented and responded that made me realise that they're not going to take offence if you challenge their idea; they really do want to discuss and learn."

S3: "It's thinking about the topic and going through all the different viewpoints in your mind and figuring out which one suits you best in a way; not just going through the positive points and the negative points and what other people say about it. I think it's 
really important to develop your own opinion about something and not just rely on what other people say."

S4: "I felt free to think for myself. Instead of being told: This is what you need to think, I could form my own opinion."

The Graduate Attributes at this institution suggests that students should adopt a critical attitude towards knowledge, and should have the ability to actively engage in the generation of innovative and relevant knowledge and understanding through inquiry, critique and synthesis. The innovative use of emerging technology, informed by a teaching framework like authentic learning, has been demonstrated to help physiotherapy students develop critical attitudes towards knowledge and authority (Bozalek \& Watters, 2014; Rowe, Bozalek \& Frantz, 2013), and this study has provided additional evidence to support those findings. The learning environment must therefore be an open space where students are equipped with the knowledge and skills that are necessary for them to question authority and take control of their own learning experiences.

\section{Empathic communication}

In response to a question regarding communication in the course, students reported the development of an empathic approach to communicating with others, allowing them to be more open and less judgmental.

S1: "I'm more willing to listen to other people's opinions and actually absorb them and think and analyse what they're saying, which I think is a really good thing because then you're not just shutting their opinions out, you care for the person and their opinion is important."

S2: "For me it made me more aware of how to go about approaching a topic with someone else. But if it was a patient asking me a question, how do I go about answering them without imposing my opinion on them, because it needs to be an informed decision from the patient's side, how do they decide that if you give them only your opinion? You need to give them both sides of a story so they can process it for themselves and actually decide."

S3: "We have to start by sharing something of the self before other people will give you something back. So I think that's what we're trying to say: it takes one person with the courage to really think deeply and write something honest and then maybe perhaps other people would open up a bit more."

S4: "I found that I'm more willing to listen to other people's opinions and think and analyse what they're saying. You're not just shutting their opinion out.. . Too often we're 
listening to other people with one ear, waiting for that pause to say, 'Yes, but.. .', to attack their opinion without really listening."

The UWC Charter of Graduate Attributes states that graduates should recognise and value communication as a tool for negotiating and creating new understanding, interacting with diverse others, and furthering their own learning. It seems clear from the student responses that they were able to consider alternative points of view that they encountered during the course, and then using those different perspectives to stimulate a reflection on their own communication. This is an important finding, as empathic communication is linked to emotional intelligence which has been implicated in broad understandings of success (Ioannidou \& Konstantikaki, 2008). In other words, success in life may be associated with the ability to communicate with empathy.

The evidence presented and resulting discussion seem to clearly demonstrate that participation in this open online course provided students with opportunities to develop a range of generic attributes that were not discipline-specific. This provides further evidence that a well-designed open online course, informed by authentic learning, has the potential to facilitate student learning in innovative ways. However, it is also clear that developing these generic attributes places additional responsibilities on teachers that are significantly more challenging than simply teaching students the knowledge and skills required for their disciplinary contexts (Laurillard, 2012).

\section{Limitations}

One of the important limitations of the study was that the researcher who conducted the focus group discussion and interviews was also the facilitator of the online course. This may have influenced students' responses and interaction during the discussions. Another important limitation was the fact that few students volunteered to participate, owing to the fact that the discussions were scheduled at a time of year when students were on clinical rotations and distributed across a large geographical region. This made it difficult to get them together in the same place, and there is a concern that the small second and third group may have affected the depth of discussion that occurred.

\section{Conclusion}

This OOC presented students with opportunities to develop ways of thinking that went beyond their discipline-specific knowledge and skills. This included the development of an approach to learning among participants that is personal and internally motivated, the ability to consider alternative points of view and acknowledge differing perspectives, opportunities to challenge the idea of knowledge and authority, and growth as empathic communicators. Well designed open online courses therefore have the potential to 
facilitate the development of generic graduate attributes, especially when the course design makes use of a theoretically informed teaching framework such as authentic learning. Participants interacted with each other in ways that would be difficult to achieve in a classroom-based course, and different ways of thinking and being emerged as participants explored complex topics related to ethical and clinical practice.

Open online courses therefore offer innovative teaching and learning opportunities that can enhance the student learning experience, especially as it relates to the development of generic graduate attributes. As social media and other collaborative online technologies become increasingly embedded in higher education, educators will need to be familiar with the context of learning in open online spaces. Finally, should educators make the decision to use open online courses to facilitate the development of graduate attributes, they should design the course around students' learning tasks rather than around content. When it comes to developing higher order outcomes like graduate attributes, what the student does is more important than what they can memorise.

Statements on open data, ethics and conflict of interest

The original audio files and transcripts are available from the author on request.

I confirm that there is no competing or conflicts of interest. 


\section{References}

Barrie, S. C. (2007). A conceptual framework for the teaching and learning of generic graduate attributes. Studies in Higher Education, 32(4), 439-458.

Beaven, T., Hauck, M., Comas-Quinn, A., Lewis, T., de los Arcos, B., \& Arcos, B. D. L. (2014). MOOCs: striking the right balance between facilitation and self-determination. MERLOT Journal of Online Learning and Teaching, 1O(1), 31-43.

Bozalek, V., \& Watters, K. (2014). The potential of authentic learning and emerging technologies for developing graduate attributes. South African Journal of Higher Education, 28(3), 1069-1084.

Cohen, L., Manion, L., \& Morrison, K. (2007). Research methods in education. Professional development in education (6th ed., Vol. 38). Abingdon, Oxon: Routledge.

Cormier, D., \& Siemens, G. (2010). Through the open door: open courses as research, learning, and engagement. Educause Review, 45(4), 31-39.

Elo, S., \& Kynga€s, H. (2007). The qualitative content analysis process. Journal of Advanced Nursing, 62(1), 107-115.

Fini, A. (2009). The technological dimension of a massive open online course: the case of the CCKo8 course tools. International Review of Research in Open and Distance Learning, 10,5 .

Herrington, J., \& Oliver, R. (2000). An instructional design framework for authentic learning environments. Educational Technology Research and Development, 48(3), 23-48.

Ioannidou, F., \& Konstantikaki, V. (2008). Empathy and emotional intelligence: What is it really about? International Journal of Caring Sciences, 1(3), 118-123.

Laurillard, D. (2012). Teaching as a design science: building pedagogical patterns for learning and technology. London: Routledge.

Ovens, P., Wells, F., Wallis, P., \& Hawkins, C. (2011). Developing inquiry for learning: reflecting collaborative ways to learn how to learn in higher education. London: Routledge.

Parker, J., Maor, D., \& Herrington, J. (2013). Authentic online learning: Aligning learner needs, pedagogy and technology. Issues in Educational Research, 23(227), 227241.

\section{https://repository.uwc.ac.za/}


Rowe, M., Bozalek, V., \& Frantz, J. (2013). Using google drive to facilitate a blended approach to authentic learning. British Journal of Educational Technology, 44(4), 594606.

Wilson, S., Liber, O., Johnson, M., Beauvoir, P., Sharples, P., \& Milligan, C. (2007). Personal learning environments: challenging the dominant design of educational systems. Journal of E-Learning and Knowledge Society, 3(2), 27-38.

Yuan, L., \& Powell, S. (2013). MOOCs and open education: implications for higher education. JISC Centre

for Educational Technology \& Interoperability Standards. Halton, Lancaster: CETIS LLP. 